San Jose State University

SJSU ScholarWorks

Master's Theses

Master's Theses and Graduate Research

1999

\title{
The effect of instruction manipulation on the academic performance of children
}

Sylvia Havadtoy

San Jose State University

Follow this and additional works at: https://scholarworks.sjsu.edu/etd_theses

\section{Recommended Citation}

Havadtoy, Sylvia, "The effect of instruction manipulation on the academic performance of children" (1999). Master's Theses. 1931.

DOI: https://doi.org/10.31979/etd.rfs4-hqbg

https://scholarworks.sjsu.edu/etd_theses/1931

This Thesis is brought to you for free and open access by the Master's Theses and Graduate Research at SJSU ScholarWorks. It has been accepted for inclusion in Master's Theses by an authorized administrator of SJSU ScholarWorks. For more information, please contact scholarworks@sjsu.edu. 


\section{INFORMATION TO USERS}

This manuscript has been reproduced from the microfilm master. UMI films the text directly from the original or copy submitted. Thus, some thesis and dissertation copies are in typewriter face, while others may be from any type of computer printer.

The quality of this reproduction is dependent upon the quality of the copy submitted. Broken or indistinct print, colored or poor quality illustrations and photographs, print bleedthrough, substandard margins, and improper alignment can adversely affect reprocuction.

In the unlikely event that the author did not send UMI a complete manuscript and there are missing pages, these will be noted. Also, if unauthorized copyright material had to be removed, a note will indicate the deletion.

Oversize materials (e.g., maps, drawings, charts) are reproduced by sectioning the original, beginning at the upper left-hand comer and continuing from left to right in equal sections with small overlaps.

Photographs included in the original manuscript have been reproduced xerographically in this copy. Higher quality $6^{*} \times 9^{*}$ black and white photographic prints are available for any photographs or illustrations appearing in this copy for an additional charge. Contact UMI directly to order.

Bell \& Howell Information and Leaming 300 North Zeeb Road, Ann Arbor, MI 48106-1346 USA

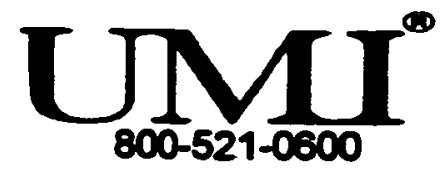





\author{
A Thesis \\ Presented to \\ the Faculty of the Department of Psychology \\ San Jose State University
}

\author{
In Partial Fulfillment \\ of the Requirements for the Degree \\ Master of Arts
}

by

Sylvia Havadtoy

December, 1999 
UMI Number: 1397729

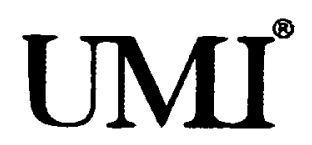

UMI Microform 1397729

Copyright 2000 by Bell \& Howell Information and Learning Company.

All rights reserved. This microform edition is protected against unauthorized copying under Title 17, United States Code.

Bell \& Howell Information and Leaming Company 300 North Zeeb Road

P.O. Box 1346

Ann Arbor, MI 48106-1346 
<smiles>[CH]</smiles> 
APPROVED FOR THE DEPARTMENT OF PSYCHOLOGY

Rodent Coupler Dr. Mary Masters mature

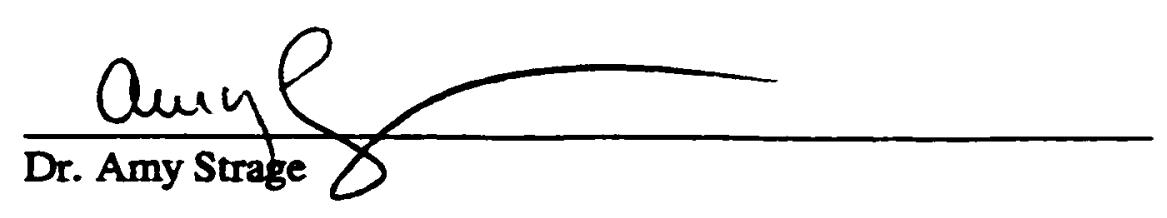

APPROVED FOR THE UNIVERSITY

William Pish 


\section{ABSTRACT \\ THE EFFECT OF INSTRUCTION MANIPULATION ON THE ACADEMIC PERFORMANCE OF CHILDREN}

by Sylvia Havadtoy

Researchers have stated that to understand the influence of motivation and cognition on academic performance, the relation between these two contexts should be examined together (Pintrich, Anderman, \& Klobucar, 1994). In the present study, 64 third-grade children completed selected reading and math items from a standardized achievement test in either a difficult, neutral, or easy instruction condition. Two-way (Instruction Condition x Teacher Ratings) analyses of variance revealed that, contrary to the research hypotheses, instruction type did not significantly influence children's reading or math scores. However, the results of the anovas and pearson product moment correlations indicated that teacher ratings of children's reading and math abilities significantly predicted children's reading and math scores. The present findings are discussed in terms of their implications for teachers and students in elementary classrooms. 


\section{ACKNOWLEDGEMENTS}

I am especially grateful for the help I received on earlier versions of this paper from Dr. Robert Cooper, Dr. Mary Masters, and Dr. Amy Strage. I would also like to thank Michele Wong and Kyle Wanshaffe for their help with this project. Finally, I would like to express my gratitude to the children, parents, teachers, and principals of the three elementary schools who participated in this project.

For: Mama, Papa, Nagymama, and Tom 


\section{TABLE OF CONTENTS}

SECTION

PAGE

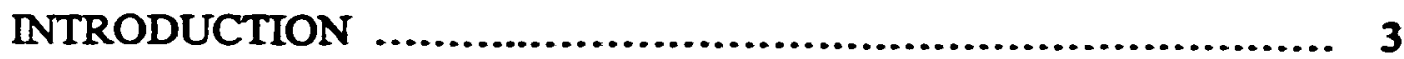

Historical Background ......................................... 4

Present Trends in Motivation and Cognition ..................... 6

Extrinsic and Intrinsic Motivation ............................... 6

Learning and Performance Goals ................................ 7

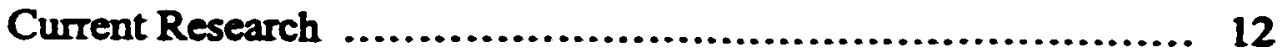

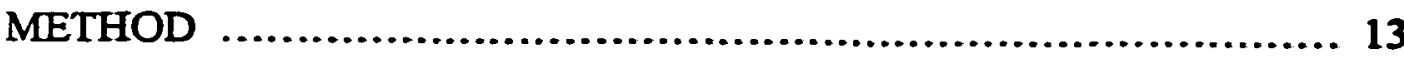

Participants .................................................. 13

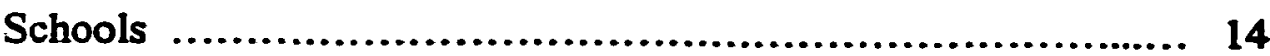

Materials and Devices ....................................... 15

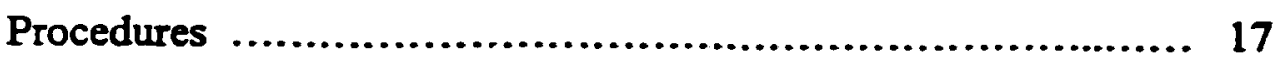

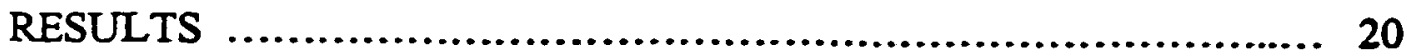

DISCUSSION ...................................................... 27

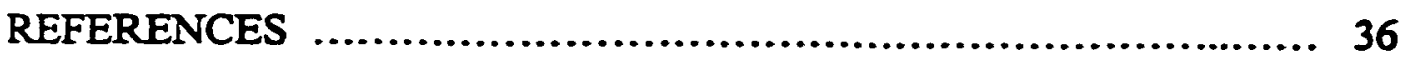

APPENDICES

Appendix A. Teacher Rating Form ............................. 38

Appendix B. Reading Performance Measure ................... 39

Appendix C. Math Performance Measure ..................... 47 


\section{LIST OF TABLES}

TABLE

PAGE

1. Order of Questions Regarding Children's Perceptions

of Their Abilities

2. Means and Standard Deviations of Children's Reading and Math Test Scores as a Function of Instruction Condition

3. Pearson Product Moment Correlations Among All variables

4. Means of Children's Ratings of Their Reading and Math Test

Performance as a Function of Instruction Condition

5. Means and Standard Deviations of Boys' and Girls' Reading and Math Test Scores as a Function of Instruction Condition 
THE EFFECT OF INSTRUCTION MANIPULATION ON THE ACADEMIC PERFORMANCE OF CHILDREN

Sylvia Havadtoy

San Jose State University

Running head: INSTRUCTION MANIPULATION

Footnote

Requests for reprints should be sent to Sylvia Havadtoy, Department of Child

Development and Family Relationships, University of Texas at Austin, Austin, TX, 78751. 


\begin{abstract}
Researchers have stated that to understand the influence of motivation and cognition on academic performance, the relation between these two contexts should be examined together (Pintrich, Anderman, \& Klobucar, 1994). In the present study, 64 third-grade children completed selected reading and math items from a standardized achievement test in either a difficult, neutral, or easy instruction condition. Two-way (Instruction Condition $x$ Teacher Ratings) analyses of variance revealed that, contrary to the research hypotheses, instruction type did not significantly influence children's reading or math scores. However, the results of the anovas and pearson product moment correlations indicated that teacher ratings of children's reading and math abilities significantly predicted children's reading and math scores. The present findings are discussed in terms of their implications for teachers and students in elementary classrooms.
\end{abstract}


The Effect of Instruction Manipulation on the Academic Performance of Children

By examining children's learning and motivation in classroom settings, researchers have discovered that children approach, think about, and complete academic tasks utilizing a variety of motivational and cognitive techniques (Deci \& Chandler, 1986, Heyman, Dweck \& Cain, 1992). For example, children's successful academic achievement outcomes may be the result of their motivation to learn specific material that they find interesting or may be the result of their desire to obtain a high grade on an exam. In both cases the performance outcomes may be the same (i.e., children receive an ' $A$ ' on their report cards), but the learning and motivational patterns which may serve to either hinder or facilitate future academic achievement may be quite different.

Researchers have discovered that in addition to motivational variables, cognitive factors also play an important role in the development of children's successful academic achievement outcomes (Pintrich, Anderman, \& Klobucar, 1994). For example, children's views about the flexibility or stability of their own intelligence can influence the type of goal-orientation strategies they adopt when approaching a challenging task. Over time, these different goal-orientations may serve to facilitate successful or unsuccessful academic achievement patterns (Bempechat, London \& Dweck, 1991).

Researchers interested in children's academic achievement patterns within classroom settings have examined the individual roles of cognition and motivation on children's academic achievement. However, the relations between these two contexts have not been examined together. Understanding the way in which a combination of 
motivational and cognitive factors may influence children's academic achievement may help us identify more specifically the aspects of motivation and cognition that influence children's successful as well as unsuccessful educational outcomes.

To examine the influence of both motivation and cognition on children's academic achievement, the present study examined the predictive relationships of different types of instructions (difficult, neutral and easy) and teacher ratings of children's reading and math abilities on children's reading and math achievement. It was hypothesized that teacher ratings of children's math and reading abilities and type of instruction would significantly predict children's reading and math achievement outcomes. Furthermore, it was hypothesized that, as compared to children in the neutral and easy instruction conditions, children in the difficult instruction condition would score significantly lower on both the reading and math section of the performance task.

\section{Historical Background}

A substantial amount of early research involving the study of motivation and learning focused on animal models of behavior and generalized the results to humans. At this time motivational psychologists were concerned with what moved a resting organism to a state of activity. Researchers interested in studying motivation examined such topics as activity level, appetites and aversions, homeostasis, chemical controls, and neural structures, as well as incentives, defense mechanisms, and the degree of motivation using primarily rats and monkeys as their subjects (Weiner, 1990).

An emerging trend in motivational research during the 1930's involved a new way of viewing motivation and its definition. For the first time, the term motivation 
became separated from the idea of learning. Initially researchers had argued that for learning to take place two things must happen. First, a response must be reinforced and second, a drive must be reduced. In other words, in order for learning to occur researchers argued that a response must be followed by a reinforcement and a reduction of a drive.

Tolman (1932), a researcher in the field of latent learning, demonstrated that reinforcement and drive reduction did not have to occur in order for leaming to take place. He found that when incentives were placed in a goal box after an animal had explored a maze, performance (not learning) was affected. His research showed that learning could take place even without the presence of a reward and the reduction of a drive. This caused psychologists in the field to conclude that the study of motivation was separate from the study of leaming. They reasoned that motivation was related to the use of knowledge but was not related to its development (Weiner, 1990).

The next conceptual step in the study of motivation and learning involved a general shift in psychology toward the area of cognition. Rather than focusing on the concept of a reward as a precursor to an automatic response, it was recognized that a reward could be a less mechanical concept and may involve a variety of different meanings and motivational factors. Thus, the concept of motivation evolved to include more complex cognitive processes than simple, mechanical responses such as drive reduction and homeostasis. As a result of this shift to include cognition in their view of motivation, researchers likened motivational research to achievement motivation and psychologists began to examine the effects of rewards on human behavior in new ways. 


\section{Present Trends in Motivation and Cognition}

Research in the area of motivation and cognition has progressed from studying animal learning in laboratory environments to studying human behavior in a variety of 'real world' settings. Specifically, researchers have been interested in the ways that motivation and learning combine to create performance outcomes in humans.

Researchers in the fields of educational and developmental psychology have examined academic performance in elementary school children to gain a better understanding of how motivation can influence children's cognition and achievement in school settings. Researchers studying leaming in a classroom environment have suggested that both motivation and cognition play important roles in fostering successful academic performance in children (Pintrich, et al., 1994). Moreover, researchers have stated that in order to understand the influence of motivation and cognition on academic performance, the contributions of these two constructs should be examined together.

\section{Extrinsic and Intrinsic Motivation}

Researchers have investigated specific aspects of motivation in an attempt to identify individual components that affect academic performance in children. Researchers interested in motivation in the context of a school setting have made the distinction between two kinds of motivation: extrinsic and intrinsic motivation (Deci \& Chandler, 1986).

Activities that are extrinsically motivated are not valued for their own sake. They require external prompts or rewards in order for children to perform them (Shaffer, 
1994). A child who participates in a particular activity only to receive a prize upon completion of that activity is said to be extrinsically motivated. On the other hand, a child who values an activity for its own sake and does not require external prompts or rewards to perform that activity is said to be intrinsically motivated (Shaffer, 1994). Children who repeatedly tackle crossword puzales because they receive personal satisfaction from solving the word clues are said to be intrinsically motivated (Hoyenga \& Hoyenga, 1984).

Evidence strongly indicates that extrinsic incentives (such as money, prizes or other tangible rewards) can serve to decrease or inhibit intrinsic motivation. When children are offered a reward to engage in an activity they normally enjoy, they become less interested in the task for its own sake once they have received the reward. Furthermore, extrinsic rewards may work to inhibit leaming. Upon receiving external rewards for their efforts, children may lose their motivation for the process of leaming itself (Hoyenga \& Hoyenga, 1984).

\section{Leaming and Performance Goals}

The term motivation includes the causes behind why individuals strive to reach a particular class of goals that involve competencies in some area. Researchers have identified these achievement goals in two ways: (a) learning goals and (b) performance goals. Both types of goals involve one's competence in a learning situation, yet the two goals result in different types of approaches to learning and often influence learning outcomes (Heyman, et al., 1992). 
Students who are interested in learning for the sake of improving their knowledge are said to engage in learning goals. Students who are motivated by learning goals have been found to value and report the use of cognitive leaming strategies and forms of selfregulation. These children view obstacles and challenges as a natural part of the learning process and are not discouraged or dissuaded by them. Learning goal-oriented children focus on increasing their existing abilities and developing new skills as situations arise for them to do so.

In contrast to children with leaming goals, children who have performance goals focus on judging and evaluating the adequacy of their abilities. They seek to obtain favorable judgements of their competence or avoid negative judgement of their competence. The difference between these two types of goals may be seen in statements such as, "I want to get an A on this test" (performance goal) versus "I want to understand why the United States was one of the last countries to enter World War II' (learning goal) (Driscoll, 1994).

Studies on learning and performance goals have provided evidence that different goals promote different motivational patterns. For example, when children are faced with a performance goal and show little confidence in their abilities, they are likely to display signs of helplessness. These children avoid challenging tasks, and if given the chance, will quit working on a task rather than persist to overcome the obstacle with which they are faced. In similar situations, children who have obtained learning goals will persist on a task even if initially that task is giving them trouble (Driscoll, 1994). 
The differences in performance between learning goal-oriented students and performance goal-oriented students seem to lie in how students interpret their failures when they do occur. Performance goal-oriented students have what has been characterized as an entity view of intelligence (Stipek, 1988). These students believe that intelligence is fixed and they interpret failure as a lack of adequate ability. Performance goal-oriented students believe that if they fail at a task, it is because they are not smart enough or good enough to succeed at it.

Leaming goal-oriented students, on the other hand, have an incremental view of intelligence (Stipek, 1988). These students believe that intelligence is flexible and changeable and they emphasize the strategies needed to complete a task successfully. Students who employ learning goals attempt to apply their abilities and work to increase them in the face of a more difficult situation. If they experience failure, learning goaloriented students believe that there is a problem with the current strategy they are using, and do not believe there is a problem with their intellectual abilities (Elliot \& Dweck, 1981).

According to this theory of goal-orientation, to do well in school, children should set challenging goals that are oriented toward learning and not performance outcomes. This suggestion is contradictory to some of the ways in which many elementary school classrooms are conducted. Typically, tests and other achievement measures are used as assessments of children's academic performance and involve the comparison of performance measures between children of similar ages and intellectual abilities. 
While different goal-orientations are thought to develop as a result of a child's particular motivation for completing a particular task, it is also important to consider learning and performance goals as stable characteristics of a particular activity rather than as inherent characteristics of a child. Some tasks such as final exams, standard achievement tests, or other academic indexes of children's abilities may cause children to have performance rather than learning goals because of the intense focus on these activities for children to perform well. In other cases, when children engage in tasks they enjoy such as reading books they find interesting or working on math problems that intrigue them, they might have learning goals. When considering if a child has a performance goal or a learning goal, it is important to consider both the characteristics of the individual child and the characteristics of the specific task at hand.

One area of research that has gained considerable attention over the past twenty years is the influence of teacher expectations on students' academic achievement. One of the most widely cited research studies in this area is Rosenthal and Fode's (as cited in Cooper, 1979) Pygmalion in the Classroom. In this study, researchers randomly selected $20 \%$ of the students from 18 classrooms in an elementary school and gave them a test of nonverbal intelligence. These students were described to their teachers as "having shown emarkable potential for academic growth" (p. 390). Eight months later, the researchers re-administered the same test of nonverbal intelligence to the group of children. Results indicated that "students in early grades for whom high teacher expectations had been induced showed significant gains in total IQ and reasoning IQ when compared to other students in their school"' (p. 390). 
Although the Rosenthal and Fode study was criticized on methodological grounds, Rosenthal (as cited in Cooper, 1979) conducted a comprehensive meta-analysis of over 300 studies which assessed expectation effects. He found that $37 \%$ of these studies reported "significant $(\mathfrak{p}<.05)$ results in a direction confirming an expectancy influence on subject behavior" (p. 391). The results of this meta-analysis clearly indicated that through their expectations for their students' performance, teachers could be in a powerful position to influence students' academic achievement in the classroom.

Not only can teachers' perceptions of their students' abilities influence students' achievement, but students' self-efficacy beliefs can also affect their performance. For example, Collins (as cited in Berliner \& Calfee, 1996) examined children's beliefs about their own mathematical abilities in relation to their math achievement. He found that even among children with different levels of abilities, "students with relatively high perceptions of self-efficacy solved more problems correctly and chose to rework more problems that they had missed than students low in perceived self-efficacy" (p. 88).

Research results concerning teacher and student expectations on academic achievement indicate that children's early elementary school experiences can have important consequences for the way in which they approach and view the process of learning throughout their lives. If children are confronted with unpleasant and unsuccessful learning experiences during the early years of elementary school, they may develop a pattern of negative views toward their own abilities and subsequent academic achievement throughout the rest of their school years. 


\section{Current Research}

Researchers interested in factors influencing the academic performance of children have sought to understand the ways that different motivational and leaming strategies might influence children's cognitions and academic performance. Bempechat, et al. (1991) conducted an experiment to examine children's conceptions of their abilities to solve a matrix. The matrix was based on a modified version of the Ravens' Progressive Matrices and contained 24 items of moderate difficulty for fifth and sixthgraders. Children were influenced to adopt either entity or incremental views of intelligence by hearing one of two sets of instructions regarding matrix solving abilities:

(a) everyone can learn to solve the problems but some kids really have the ability and some don't (entity), and (b) some kids are good at solving the problems right away, while some aren't, but everyone can get them eventually (incremental).

Results indicated that children who were led to believe they either had the ability to solve the matrix or they did not (entity condition) adopted a performance goalorientation toward solving the matrix. In contrast, children who were led to believe that they could solve the matrix if they tried hard enough (incremental condition) adopted a learning goal-orientation. Interestingly, there were no overall mean differences in matrix solving accuracy between children in each condition. The authors concluded that cognitions and affect are affected by children's beliefs about their abilities, but actual performance is not.

Why is it that when children's beliefs about their abilities are manipulated, their cognitive approaches to an academic task also change but their actual performance 
outcomes do not? Researchers have demonstrated that different factors such as type of motivation (performance or leaming goal-orientation) and views of intelligence (entity or incremental) influence the way children approach academic tasks, yet how might these factors influence performance outcomes in children? If instructions conceming a task can influence children's thoughts about ways to approach that task, can instructions also influence children's actual performance on that task?

Previous research has shown that threatening factors which may cause individuals to evaluate their existing test-taking or intellectual abilities may be capable of disrupting subsequent performance (Steele \& Aronson, 1995). The present study sought to determine the effect of different types of instructions (difficult, neutral and easy) on the reading and math performance of third-grade children. To control for cognitive ability, teacher ratings of their students' reading and math abilities were also examined as predictors of children's reading and math performance.

As previously stated, it was hypothesized that instruction type would significantly influence children's reading and math performance scores. Furthermore, it was hypothesized that children in the difficult instruction condition would score significantly lower on the performance measure as compared to children in the neutral and easy instruction conditions.

\section{Method}

\section{Participants}

Sixty-four third-grade children between the ages of 8 and 10 years $(M=8.4)$, recruited from three Califomia San Fransisco bay area elementary schools, were selected 
to participate in the present experiment upon their parents' consent. Thirty-eight boys and 26 girls were included in this study. Children were randomly assigned to the instruction conditions and there were slightly more boys than girls in the easy ( $n=15, \underline{n}$ $=9)$ as compared to the neutral $(\underline{n}=10, \underline{n}=8)$ and difficult $(\underline{n}=13, \underline{n}=9)$ instruction conditions.

The proportion of students whose parents returned signed consent forms to include their children in this research study varied among different classrooms and between the three elementary schools. Each school had a total of 20 students per thirdgrade classroom. For the first school, students from four different classrooms participated in this study. Sixteen students participated from the first classroom, 12 from the second, and nine students each from the third and fourth classrooms. For the second school, students from two classrooms participated in this study. Seven students participated from the first classroom, and eight students participated from the second classroom. For the third and final school, 3 students from the same classroom participated in this study.

Schools

Data obtained from the 1997-98 school year, the most recent year for which records were available, reflected the following characteristics of the three elementary schools from which children were recruited for this study. The first school had a population of 456 students with an average of 19 students per third-grade classroom. The ethnic enrollment included 13\% Hispanic, 19\% Asian, 1\% Pacific Islander, 3\% Filipino, 0\% Native American, 3\% African American, and 61\% Caucasian students. The second 
school had a comparable population of 400 students with an average of 20 students per third-grade classroom. This school served a population of 400 students, $82.5 \%$ of whom were Caucasion. Data reflecting student demographics, classroom size and size of the student population were not available for the third elementary school involved in this study.

\section{Materials and Devices}

Teacher Ratings of Students' Competence. Teachers were given a student ability rating form for each of their students who participated in the study. They were asked to use a Likert scale ranging from 1 (yery low) to 7 (very high) to rate their students' level of competency along six dimensions including reading and math ability. Only the reading and math ratings were used in the analyses for this study. The other four items were simply used as filler items to disguise the focus of the rating forms. A copy of this form may be seen in Appendix A.

Performance Measure. Items from the reading and math section of the 1964 edition of the Stanford Achievement Test Primary II Battery designed for children in the third-grade were used as test questions. For ease of administration, only those reading items that were no more than five lines in length were considered for inclusion. Of these items, 20 were selected using a random number table and included in the reading section of the present study. Similarly, a random number table was used to select one item from each two adjacent math items for a total of 30 items in the math section of the present study (see Appendices B and C for a copy of the reading and math performance measures). 
Perceived Reading Performance Questions, To assess the degree of perceived difficulty of the reading items, students were asked to answer two questions after completing the reading items: (a) how hard did you think the reading section was going to be, and (b) how hard was the reading section? Answer choices were based on a Likert scale ranging from 1 (very hard) to 4 (very easy).

Perceived Math Performance Questions. To assess the degree of perceived difficulty of the math items, students were asked to answer the following two questions after completing the math items: (a) how hard did you think the math section was going to be, and (b) how hard was the math section? Answer choices were based on a Likert scale ranging from 1 (very hard) to 4 (very easy).

Overall Perceived Difficulty Questions. To assess the degree of perceived difficulty for both the reading and the math items, students were asked to answer two questions: (a) how well do you think you will do on this entire test, and (b) how well do you think you just did on this entire test? The former question was presented before students began to complete the entire performance measure and the latter question was presented after students had completed the entire performance measure. Answer choices ranged from 1 very poorly to 4 yery well.

The last three items in both the reading and math performance measures were relatively easy items and were not used for data analysis purposes. These items were included in order to ensure that students who completed all of the items would complete the performance measure with a successful problem solving experience. For students 
who did not reach these items because they ran out of time, the debriefing provided them with a source of encouragement regarding the adequacy of their academic abilities. Procedure

Children were tested during regularly scheduled school hours. A female experimenter escorted children in small groups into a room where the experiment took place. Children sat in chairs with writing space in front of them. The experimenter passed out test booklets containing the performance measures and asked the children to leave the booklets face down on their desks until they were instructed to begin their task.

Half of the tests contained the reading section first followed by the math section, while the other half of the tests contained the math section first followed by the reading section. Every other group of children received a test booklet containing the reading section first, while the alternate groups of children received a test booklet that contained the math section first. Depending on the instruction condition, the experimenter read either the difficult, neutral, or easy instructions to the group of children as described below.

Difficult Instructions. "This test will help me understand the kinds of things you have learned in school so far. It will probably be difficult for many of you. It has a reading section and a math section. I've given it to other students your age and they have found it difficult, but please take it seriously and try your best."

Neutral Instructions. "This test will help me understand the kinds of things you have learned in school so far. It has a reading section and a math section. I've given it to other students your age. Please take it seriously and try your best." 
Easy Instructions. "This test will help me understand the kinds of things you have learned in school so far. It has a reading section and a math section. It will probably be easy for many of you. I've given it to other students your age and they have found it easy, but please take it seriously and try your best."

Following the instructions, the experimenter asked the children to indicate on their test booklets how well they thought they would do on the entire performance measure. The experimenter then said, "When you see the word 'stop" on your test, please turn your test face down on your desk and sit quietly until you are instructed to continue. You may now tum your test over and begin."

The experimenter sat down in the front of the room and worked quietly. Students were given 13 minutes to complete the math section and 10 minutes to complete the reading section of the performance measure. After calling time for the first section of the performance measure, the experimenter asked the children to indicate how hard they thought the first section of the test was going to be and also to indicate how hard the first section actually was for them. The experimenter then said, "You may now begin the next section."

After calling time for the second section of the performance measure, the experimenter asked children to indicate how hard they thought the second section of the test was going to be and also to indicate how hard the second section actually was for them. The experimenter then asked children to indicate how well they thought they just did on the entire performance measure. A summary of the order in which children were asked to respond to questions on the performance measure may be seen in Table 1. 
Table 1

Order of Questions Regarding Children's Perceptions of Their Abilities

How well do you think you will do on this test?

How hard did you think the reading/math section was going to be?

How hard was the reading/math section?

How well do you think you just did on this entire test? 
The experimenter then said, "Thank you very much for helping me today. I want to let you know that some of the questions on your test were designed for older children and were purposefully difficult to solve. Don't worry if you didn't know the correct answer to every question, you were not supposed to know the answers to many of the questions. Thank you again for your help. You all did a great job." The experimenter gave a sticker to each of the children for their help in the study and then walked all of the children back to their respective classrooms.

\section{Results}

To ensure that groups of boys and girls did not differ with respect to reading and math ability, 2-way (Gender $x$ Instruction) analyses of variance were conducted on teacher ratings of children's reading and math abilities. For teacher reading ratings, no significant main effect emerged for gender, $[E(1,58)=.50, p=.48]$ or instruction condition $[E(2,58)=.40, p=.67]$. There was no significant interaction between gender and instruction condition, $\mathrm{E}(2,58)=.16, \mathrm{p}=.86$.

For teacher math ratings, however, a significant main effect emerged for gender $[E(1,58)=4.56, \mathbb{R}<.05]$ but no significant main effect emerged for instruction condition, $E(2,58)=1.24, p=.30$. Teacher ratings of math ability were significantly higher for boys $(M=5.39)$ as compared to girls $(M=4.69)$. There was no significant interaction between gender and instruction condition, $\mathrm{E}(2,58)=.24, \mathrm{p}=.79$.

For the items that were selected for the present study, children's performance on the reading section ranged from a minimum score of 5 to a maximum score of $24(M=$ 
15.72) out of a total possible 24. Children's scores on the math section ranged from a minimum score of 5 to a maximum score of $28 \underline{M}=19.27)$ out of a total possible 30 . Comparing children's performance on the reading and math performance measure as a function of instruction condition revealed interesting, although not statistically significant, findings $[\mathrm{F}(2,61)=.75, \mathrm{p}=.48]$ and $[\mathrm{F}(2,61)=1.76, \mathrm{p}=.18]$, respectively. A trend in the data indicated that, contrary to the researcher's hypothesis, children scored slightly higher on both the reading and math sections of the performance measure in the difficult followed by the neutral and easy instruction conditions. A summary of these findings may be seen in Table 2.

Pearson correlation coefficients were calculated for all pairwise combinations of variables and are reported in Table 3. Significant positive correlations emerged between many of the variables suggesting interrelations between many of them. Children's reading achievement scores were significantly correlated with their math scores [r $(62)=$ $.59, \mathrm{p}<.001]$, teacher ratings of their reading abilities $[\mathrm{r}(62)=.56, \mathrm{p}<.001]$, how hard children thought the reading section was going to be $[r(59)=.43, \mathrm{p}<.01]$, and how hard children indicated the reading section actually was for them, $\mathrm{r}(59)=.54, \mathrm{p}<.001$. Interestingly, children's reading achievement scores were not significantly correlated with how well they thought they would perform on the entire achievement measure, $\underline{r}$ $(55)=.07, p=.62$. One explanation of these findings is that children may value math skills more than reading skills when predicting their overall academic performance.

Children's math achievement scores were significantly correlated with teacher ratings of their math abilities $[\mathrm{r}(62)=.51, \mathrm{D}<.001]$, how hard children thought the math 
Table 2

Means and Standard Deviations of Children's Reading and Math Test Scores as a Eunction of Instruction Condition

\begin{tabular}{|c|c|c|c|c|}
\hline \multirow[b]{2}{*}{ Instructions } & \multicolumn{2}{|c|}{ Reading Test } & \multicolumn{2}{|c|}{ Math Test } \\
\hline & $\mathbf{M}$ & SD & $\mathbf{M}$ & $\mathbf{S D}$ \\
\hline Easy & 14.79 & 5.30 & 18.00 & 5.39 \\
\hline Neutral & 15.94 & 4.50 & 19.50 & 3.93 \\
\hline Difficult & 16.55 & 4.86 & 20.45 & 3.71 \\
\hline
\end{tabular}


Table 3

Pearson Product Moment Correlations Among All variables

$\begin{array}{lllllllllll}\text { Variables } & 1 & 2 & 3 & 4 & 5 & 6 & 7 & 8 & 9 & 10\end{array}$

1. Teacher Reading Rating

2. Teacher Math Rating $.58^{*}$

3. Reading Score $.56^{*} .23$

4. Math Score $.39 * .51^{*} .43^{*}$

5. How well think on entire test $\quad .19 \quad .34^{*} .07 \quad .29 *$

6. How hard think reading $\quad \begin{array}{llllll}.24 & .08 & .43^{*} & .17 & .35^{*}\end{array}$

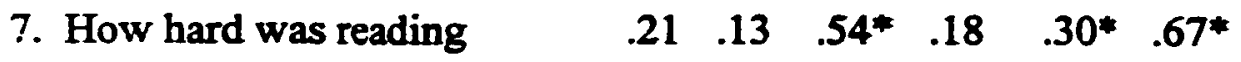

$\begin{array}{llllllllll}\text { 8. How hard think math } & & .17 & .24 & .17 & .33^{*} & .28^{*} & .38^{*} & .31^{*}\end{array}$

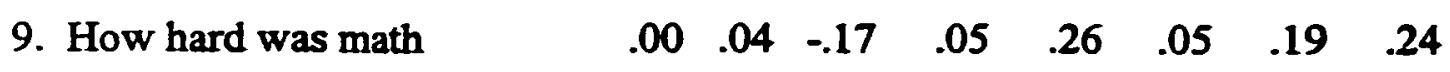

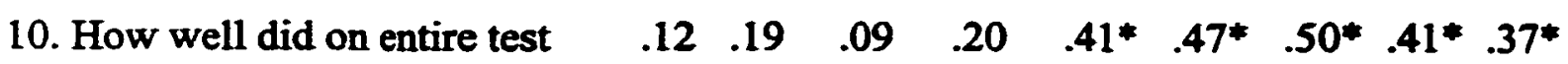

$* \mathrm{p}<.05$ 
section was going to be $[\mathrm{r}(62)=.33, \mathrm{R}<.001]$, and how well children thought they would do on the entire achievement measure, $\mathrm{I}(55)=.29, \mathrm{p}<.05$.

Children's beliefs about how well they thought they would perform on the entire performance measure were significantly correlated with how hard they thought the math $[\mathrm{r}(55)=.28, \mathrm{p}<.05]$ and reading $[\mathrm{r}(52)=.35, \mathrm{p}<.01]$ sections were going to be and how well they thought they just did on the entire performance measure, $I(52)=.41, R<$ .01. A significant positive correlation also emerged between how hard children thought the math section was going to be and how hard they thought the reading section was going to be, $\mathrm{r}(59)=.38, \mathrm{p}<.01$.

In general, children felt relatively confident about their abilities to do well on the entire performance measure both before beginning to work on any of the items $M=$ 3.35) and after completing all of the items $(M=3.11)$. There were no significant differences among children's responses for all six questions concerning their perceptions of the items on the performance measure and their abilities as a function of easy, neutral, and difficult instructions. Mean responses for each of the items concerning children's perceptions of the performance measure and their abilities for each instruction condition may be seen in Table 4.

To examine the relationship between instruction manipulation and children's reading and math achievement, 2-way (Instruction Condition $\mathbf{x}$ Teacher Rating) analyses of variance were conducted on children's reading and math test scores. A median split was conducted on teacher ratings of children's reading and math abilities to categorize 
Table 4

Means of Children's Ratings of Their Reading and Math Test Performance as a Function of Instruction Condition

Instructions

Questions

1. How well do you think you will do on this entire test?

2. How hard did you think reading section was going to be?

3. How hard was the reading section?

4. How hard did you think the math section was going to be?

5. How hard was the math section?

6. How well do you think you just did on this entire test?
$3.36 \quad 3.28$

2.71

2.78

3.00

\subsection{6}

2.89

2.77

$2.71 \quad 2.56$

2.73

$2.21 \quad 2.06$

$3.10 \quad 2.94$

3.27

Note. On items 1 and 6 the scale ranged from 1 (yery poorly) to 4 (yery well). On items $2,3,4$, and 5 the scale ranged from 1 (very hard) to 4 (very easy). 
children's abilities as either high (a reading or math rating greater than 5) or low (a reading or math rating less than or equal to 4 ).

For children's reading achievement, no significant main effect emerged for instruction condition, $\mathrm{E}(2,58)=.51, \mathrm{MSE}=10.42, \mathrm{p}=.61$. A significant main effect was found for the categorical reading rating variable, $E(1,58)=13.56, \mathrm{MSE}=279.53, \mathrm{p}$ $<.01$. Children who were rated higher $(M=18.00)$ in reading performed better than those rated lower $(M=13.71)$ in reading. Finally, there was no significant interaction between instruction condition and categorical reading rating, $\mathrm{E}(2,58)=.25, \mathrm{MSE}=5.23$, $p=.78$. Consistent with the results of this analysis, a one-way analysis of covariance of the instruction factor with teacher rating of reading ability as the covariate revealed no significant effect of instruction, $E(2,60)=.50, p=.61$.

The pattern of results for the math test was similar to that of reading test. For math achievement, there was no significant main effect of type of instruction on children's math performance, $\mathrm{E}(2,58)=1.40, \mathrm{MSE}=26.30, \mathrm{R}=.26$. A significant main effect of the categorical math rating variable emerged, $E(1,58)=4.55, \mathrm{MSE}=86.23, \mathrm{p}<$ .05 . Children who were rated higher $(M=20.85)$ in math by their teachers performed significantly better than those who were rated lower $(M=18.18)$ in math. There was no significant interaction between instruction condition and categorical math rating, $E(2,58)$ $=.60, \mathrm{MSE}=11.34, \mathrm{p}=.55$. Consistent with the results of this analysis, a one-way analysis of covariance of the instruction factor with teacher rating of math ability as the covariate revealed no significant effect of instruction, $E(2,60)=.93, p=.40$. 
Only small mean gender differences in children's reading and math scores between instruction conditions were observed (see Table 5). To test the significance of these differences, 2-way (Instruction Condition $x$ Gender) analyses of variance were conducted on children's reading and math test scores. For reading achievement, there was no significant main effect for gender $[E(1,58)=.18, \mathrm{MSE}=4.32, \mathrm{p}=.68]$ and, as expected, no significant main effect for instruction condition, $E(2,58)=.78, \mathrm{MSE}=$ $19.18, p=.46$. There was no significant interaction between gender and instruction condition, $\mathrm{E}(2,58)=.83, \mathrm{MSE}=16.79, \mathrm{p}=.44$

The pattern of results for math achievement was similar to that of reading achievement. For children's math achievement, there was no significant main effect of gender $[E(1,58)=.83, \mathrm{MSE}=16.70, \mathrm{p}=.37]$ and as expected, no significant main effect for instruction condition, $E(2,58)=2.24, \mathrm{MSE}=45.12, \mathrm{p}=.12$. There was no significant interaction between gender and instruction condition, $\mathrm{E}(2,58)=1.18, \mathrm{MSE}=$ $29.04, p=.31$

\section{Discussion}

The present study attempted to determine the predictive relationships between instruction type and teacher ratings of students' math and reading abilities on the academic performance of third-grade children. It was hypothesized that children's performance on the math and reading tests would be influence by the types of instructions they received. It was expected that overall performance scores would be significantly lower in the difficult instruction condition as compared to both the easy and neutral 
Table 5

Means and Standard Deviations of Boys' and Girls' Reading and Math Test Scores as a Eunction of Instruction Condition

\begin{tabular}{lcccccc}
\hline & \multicolumn{2}{c}{ Reading Test } & & \multicolumn{2}{c}{ Math Test } \\
\cline { 2 - 5 } & & & & & \\
Instructions & Boys & Girls & & Boys & Girls \\
& & & & & \\
\hline Easy & $14.73(4.83)$ & $14.89(6.31)$ & & $18.93(5.61)$ & $16.44(4.90)$ \\
Neutral & $17.40(3.86)$ & $14.13(4.82)$ & & $20.20(3.77)$ & $18.63(4.21)$ \\
Difficult & $15.92(4.92)$ & $17.44(4.90)$ & & $20.08(4.27)$ & $21.00(2.87)$ \\
& & & & & & \\
\hline
\end{tabular}


instruction conditions. It was also hypothesized that teacher ratings of children's reading and math abilities and instruction condition would significantly predict children's reading and math performance scores. However, results of the analyses indicated that only teacher ratings predicted children's reading and math test performance.

It seems that such short and cursory instructions as the ones employed in this study are not enough to influence children's expectations of their abilities and their subsequent performance on an academic task. Children, at least by third grade, may be aware of the extent of the competence of their own abilities and may not seem swayed by negative or positive predictions regarding their up-coming performance on an academic task. Even after children's reading and math abilities were taken into consideration, instruction manipulation did not significantly predict children's academic achievement.

A small but interesting pattern of results emerged, however, among children's average reading and math achievement scores between the three instruction conditions (difficult, neutral, and easy). Slight differences emerged in children's achievement scores as children performed a little bit better under difficult instructions and only slightly worse under neutral and easy instructions, respectively. It is unclear why this pattern of data emerged. A possible explanation is that children who thought the test items were going to be difficult really tried to answer them carefully and correctly. In contrast, children who thought the test items were going to be easy maybe didn't pay as close attention to their work and missed a few more items due to carelessness. Perhaps with a larger sample size, this pattem of data would be more robust and thus, more easily interpreted, or this trend may disappear. 
These findings may also be due to the discrepancy between the kinds of math and reading items that children were expecting and the type of items they were faced with on the performance measure. Those children who expected difficult items to appear on the performance measure as a result of difficult instructions were not surprised to see the difficult items on the performance measure. However, children who heard neutral or easy instructions may have expected easier items and consequently may have been a little unnerved by the difficult items on the performance measure. This discrepancy between expectations and actual level of difficulty of the items on the performance measure may also have caused children to perform slightly below the children in the difficult instruction condition.

Overall, teachers were found to be accurate evaluators of their students' reading and math abilities. Significant positive correlations emerged between teacher ratings of children's reading and math abilities and children's reading and math performance. A significant positive correlation also emerged between children's reading and math scores. These findings indicate that at the third-grade level, children may perform at a generally competent level in school. The relationship between children's reading and math performance, accounting for $18 \%$ of the variance in children's academic achievement, may be due to a general factor of intelligence or school ability. Although statistically significant, this relationship still leaves $82 \%$ of the variance in children's academic achievement unaccounted for. Future studies should address possible variables that may also be related to children's academic achievement at the third-grade level such as children's relationships with their peers, teachers, and parents. 
It is unclear why teacher ratings of students' math abilities did not predict students' reading scores, while teacher ratings of students' reading abilities significantly predicted students' math scores. It may be that when teachers rated their students on reading ability, they rated them on a more general index of school achievement. In contrast, when teachers rated their students on math ability, they were rating them on a much more specific academic dimension. It is also possible that a number of different factors may have influenced teacher ratings of their students' abilities such as a student's physical attractiveness, a teacher's past history with their student, and/or the student's personality type.

Finally, interesting findings emerged concerning children's thoughts about their own abilities and future competencies in both reading and math subject areas. Children indicated fairly accurate ratings of their abilities in reading and math subject areas. Children who performed well on the reading and math sections of the performance measure indicated that they thought these sections were going to be relatively easy for them and that they would do relatively well on these items. Upon completion of the reading and math items, children also indicated that they thought they performed relatively well on the entire performance measure. Conversely, children who thought the reading and math items were going to be hard had less confidence in their abilities, performed less well on the reading and math items, and indicated that they did not think they performed well on the entire performance measure.

It is important to consider different reasons for children's achievement outcomes on the reading and math performance measure of this study. It is possible that the 
children whose parents gave them permission to be included in this study were already children who performed relatively well in school. Thus, the samples of children from each of the three elementary schools included in this study may have not been representative of the entire student population at those three schools. Perhaps the parents of children who were already having trouble in school did not wish for their children to take yet another standardized test and perhaps subject themselves to further feelings of inadequacy.

To include children of a variety of intellectual abilities, children were randomly assigned to each of the three instruction conditions. In addition, the results of analyses of variance indicated that teacher ratings of children's reading abilities did not differ for boys and girls and across instruction condition. However, teacher ratings of boys' math abilities were significantly higher than teacher ratings of girls' math abilities despite the fact that there were no significant differences between boys' and girls' actual math performance. These results indicate that, when compared to their female students, teachers rated their male students as having higher mathematics abilities. These teacher expectations for their students' performance can have important consequences for later academic performance.

Implications of Present Findings and Future Directions

Important implications can be drawn from the present results. First, this study supports the notion that educators may not as easily be able to influence their students' expectations of their own academic performance simply through a set of short instructions. While it is expected that teachers can encourage and foster children's 
learning in the classroom through positive reinforcement strategies and praise, it seems that one-time negative or positive predictions of children's performance may not directly influence children's immediate expectations of their own achievement outcomes.

It is also possible however, that the reason children's performance scores were not affected by the instructions used in this study was because the instructions were not effective in changing children's perceptions of their abilities. It is more likely that teachers can have an important influence on their students' academic achievement as long as they are able to change children's perceptions of their abilities. As long as teachers give their students positive instructions that enhance children's perceptions of their capabilities to do well in school, teachers' influence on children's academic achievement will be positive.

These results indicate that children at the third-grade level are relatively confident about their academic abilities in math and reading. In moderation, such a sense of accomplishment and aptitude at the early elementary grades is a positive trait for children to possess. Even in the face of below average performance, as long as children receive appropriate guidance from their teachers enabling them to correct and learn from their mistakes, a healthy amount of confidence in one's abilities is a positive way to approach the challenge of many academic tasks.

More research concerning the role of motivational and cognitive variables in children's academic performance must be conducted to further our present understanding of how these factors specifically influence actual performance in academic settings. Future research should examine the effect of different types of instructions on a variety of 
school-related tasks. It would be interesting to see the influence of difficult, neutral, or easy instructions on students' performance on tasks that require different types of cognitive strategies such as spatial ability or logical reasoning tasks.

In addition, it is important to consider the extent to which different people in children's lives (i.e., teachers, peers, and parents) are able to influence children's expectations about their own abilities through different instructions. It may be that in the present study, children did not view the experimenter as a credible source of information concerning the perceived difficulty or ease of an up-coming academic task. Research has shown that teacher expectations can have powerful influences on children's achievement (Cooper, 1979) and future studies should further address this issue.

More research needs to be conducted concerning teachers' roles in children's learning and motivation before the exact nature of teachers' influence on their students' expectations of their own performance becomes clear. Perhaps a single set of instructions is not enough to negatively or positively influence children's academic expectations but a set of instructions or predictions about children's performance over time may exert more powerful and lasting influences on children's expectations and subsequent academic achievement.

Finally, it is important to conduct this type of research on populations of children of varying ages, grade levels, and cognitive abilities. Perhaps younger or leamingdisabled children are more susceptible to the influence of their teachers' positive or negative predictions of their abilities. It could also prove valuable to conduct these types 
of studies in a longitudinal manner to examine the influence of different types of instructions on children's academic achievement over a longer period of time.

Overall, the present findings have contributed to existing information about how children think about the potential successes or failures of their own academic abilities. It is imperative that researchers continue to find ways to maximize children's learning and motivation patterns in educational settings so that teachers, and others who are in a position to influence children's leaming, may continue to provide children with teaching practices that best meet their motivational and cognitive needs. 


\section{References}

Bempechat, J., London, P., \& Dweck, C. S. (1991). Children's conceptions of ability in major domains: An interview and experimental study. Child Study Joumal 21(1), 11-36.

Berliner, D. C. \& Calfee, R. C. (1996). Handbook of educational psychology. New York, NY: Simon and Schuster Macmillan.

Burroughs, S. G. (1991). The implications for effective education of understanding pupil motivation in schools as a multi-dimensional model. International Journal of Adolescence and Youth, 2 , 251-274.

Cooper, H. M. (1979). Pygmalion grows up: A model for teacher expectation communication and performance influence. Review of Educational Research 49(3), $389-410$.

Deci, E. L. \& Chandler, C. L. (1986). The importance of motivation for the future of the LD field. Journal of Learning Disabilities, $19,587-594$.

Driscoll, M. P. (1994). Psychology of learning for instruction. Needham Heights, MA: Allyn \& Bacon.

Elliot, E. S., \& Dweck, C. S. (1981). Children's achievement goals as determinants of learned helplessness and mastery-oriented achievement patterns: An experimental analysis. Unpublished manuscript, Harvard University, Cambridge, MA. In A. Lesgold \& R. Glaser (Eds.), Foundations for a psychology of education (pp. 87-136). Hillsdale, NJ: Erlbaum. 
Galloway, D. L., Rogers, C. \& Armstrong, D. (1995). Motivational styles in English and Mathematics among children identified as having special educational needs. British Joumal of Educational Psychology, 65, 477-487.

Heyman, G. D., Dweck, C. S., \& Cain, K. M. (1992). Young children's vulnerability to self-blame and helplessness: Relationship to beliefs about goodness. Child Development 63, 301-415.

Hoyenga, K. B. \& Hoyenga, K. T. (1984). Motivational explanations of behavior. (pp.19-23). Belmont, CA: Brooks/Cole.

Pintrich, P. R., Anderman, E. M., \& Klobucar, C. (1994). Intraindividual differences in motivation and cognition in students with and without learning disabilities. Journal of Leaming Disabilities, 27(6), 360-370.

Shaffer, D. R. (1994). Social and Personality Development. Belmont, CA: Brooks/Cole.

Steele, C. M., \& Aronson, J. (1995). Stereotype threat and the intellectual test performance of African Americans. Journal of Personality and Social Psychology. 69(5), 797-811.

Stipek, D. J. (1988). Motivation to leam. Needham Heights, MA: Allyn and Bacon.

Tolman, E. C. (1932). Purposive behavior in animals and man. New York: Appleton-Century-Crofts.

Weiner, B. (1990). History of motivational research in education. Journgl of Educational Psychology, 82, 616-622. 
Appendix A

Teacher Ratings of Competence

To: Elementary School Teachers

Re: Student Ability Ratings

Dear Teachers,

Please use the scale below to rate your student, the following dimensions. For each dimension, please circle only one number that you feel best describes your student's ability on that dimension

ID \#

$\begin{array}{lllllll}1 & 2 & 3 & 4 & 5 & 6 & 7\end{array}$

Very Low

Average

Very High

Language Skills

$\begin{array}{lllllll}1 & 2 & 3 & 4 & 5 & 6 & 7\end{array}$

Reading Ability

12

2

3

4

5

6

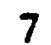

Athletic Ability

12

3

4

5

6

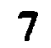

Math Ability

12

3

4

$\begin{array}{lll}5 & 6 & 7\end{array}$

Motivation to Succeed

12

Willingness to Seek Help

12

3.

4

5

67

The information that you provide here will be used for data analysis purposes only. This information will not be released to the child, their parents, or other teachers in the child's school. Information about the classroom from which each child's rating comes from will be destroyed and will not be maintained for our records.

Your responses are very important to us, and we appreciate your willingness to aid us in this part of our study. Thank you for your time and if you have questions or concerns about this study please do not hesitate to call the principal investigator, Sylvia Havadtoy at (408) 924-5600.

Sincerely,

Sylvia Havadtoy

MA Candidate, San Jose State University 
Appendix B

Reading Performance Measure

Johnny laughed and laughed. He thought the cartoon was very 1 pretty funny sloppy exciting

Judy likes to paint with dark colors. Her favorite 2 is blue.

2 name light color dress

Good teeth are important to your health. One way to have good teeth is to keep them clean. You should brush your 3 at least twice a day. Brushing your teeth will help to keep you 4

3 hair clothes teeth mouth

4 well young sick tired

Jean likes to read. Her little brother, Tommy, likes to make buildings with blocks. After school, Jean often sits down with a 5 , while Tommy $\underline{6}$ with his blocks.

$\begin{array}{lllll}5 & \text { dress } & \text { game } & \text { book } & \text { picture } \\ 6 & \text { runs } & \text { reads } & \text { draws } & \text { builds }\end{array}$


On her vacation, Sally went to a ranch. She enjoyed watching the cowboys round up the 1 while she rode along with them on a 8

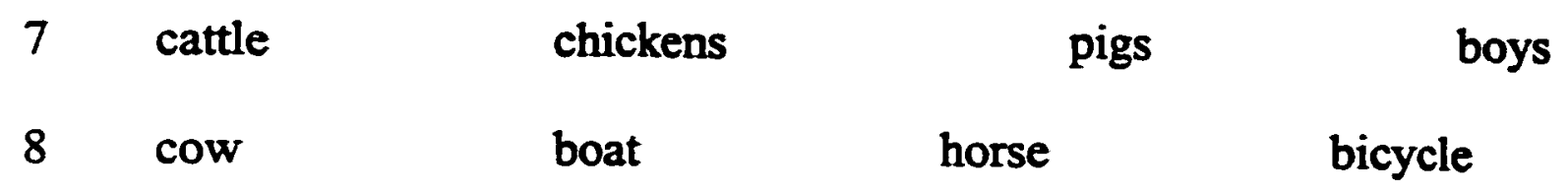

Dick wanted to play Indians. He made himself a bow. He used a piece of 9 He tied a piece of _10_ from one end of the bow to the other. 9 wood glass stone wool

10 string ball stone straw

Bert went to the ticket window in the bus station. He bought a bus $\mu_{-}$to the city.

11 train ticket program schedule

The dog ran after Jack. Down the road they went. Jack was running $\underline{12}$.

12 behind slowly back ahead 
Tom and Joe are very different. Tom is fat and Joe is 13 . Tom moves slowly; Joe moves 14

13 tall short thin weak

14 quickly softly noisily awkwardly

Margaret said, 'Mother, I haven't had anything to eat since lunch. I think

I'll die of $\underline{\underline{15}}$

15 thirst fatigue hunger fear

Mary can wash her doll's dresses, but her mother won't let her 16 them. Mother is afraid Mary will burn herself.

16 wear cut buy iron

Peggy and Sally always wear the same type of dress but of different colors.

For example, if Peggy's dress is blue, Sally's dress is usually _ 17

17 blue pink smaller new 
The boy scouts pitched their tent in a clearing in the forest. After tying the flaps of the 18 , they walked among the 19 18 clearing tent bed forest 19 trees vegetables corn buildings

Although Robert has leamed to read Spanish, he cannot _ 20_ it very well.

20 hear play paint write

Mr. Jones was going to water the lawn. He took the 21 out of the shed.

21 hoe mower hose rake

It keeps out the bugs. It lets in air. It is made of metal. It is a

22 window curtain screen shutter
Although Ray never missed school before, on Thursday he was 23 for the first time.
23 late
early
absent
on time 
Karen's purse fell on the floor beneath her chair. She had to lean down and reach 24 the chair to get it.

24 over across

through

under

John has a younger brother named Bob and two older sisters named Alice and Ruth. Therefore, Alice has two $25 \quad$ brothers, and the youngest child is 26

25 twin fine older younger

26 Bob Alice Ruth Baby Sue

The most important food plant are the grains. Grains are grown all over the world. Wheat, barley, oats, rice, and corn are the most important 27 27 grasses grains food vegetables

Mrs. Smith uses a great deal of salt and pepper in her cooking. Some people find her cooking much too 28

28 sweet sour spicy thick 
France is in Europe. Europe is east of the United States. The United States is 29 of France.

29 south

west

southwest

north
Australia, the smallest of the world's continents, lies out in the Pacific
Ocean southeast of Asia. It is sometimes called the island $\stackrel{30}{\longrightarrow}$ as it is surrounded by 31
30 ocean rock country continent
31 the ocean Asia the world land

When Alaska became the $49^{\text {th }}$ state, Texas no longer was the largest state of the Union in 32 . Califormia, which had been the $2^{\text {nd }}$ largest, became the 33_ largest _ 34 _.

32 population altitude lakes area

$331^{\text {st }} \quad 3^{\text {rd }} \quad 2^{\text {nd }} \quad 4^{\text {th }}$

34 capital county union state 
Joan is not a very good tennis player. She _ 35 - wins when she plays at school.

35 usually always often seldom

Larger numbers of people require larger numbers of government services.

Because of the rapid increase in population of cities immediately after World War II, city governments faced a demand for __ 36 _ public services.

36 somewhat fewer somewhat more considerably more the same

Betty sat by the brook in the meadow. She saw the clear water running over the pretty pebbles. She reached into the 37 and picked up one of the _ 38 She said, "My, what a _39_pebble.

37 meadow dirt brook river

38 pebbles fish sticks beads

39 huge ugly dirty pretty

Alice was playing with her new dolls. Suddenly she 40 _the telephone ring.

40 saw heard felt knew 
Susy cried and cried. She thought the movie was very 41

$\begin{array}{llll}41 & \text { pretty } & \text { sad } & \text { sloppy } \\ & \text { exciting } & & \end{array}$

Al's puppy, Woofer, kept running away. To keep Woofer at home, Al's father built a 42 around the back yard.

42 garden fence walk lawn 
Appendix C

Math Performance Measure

DIRECTIONS: Look at each example carefully to see what you are to do. Find the answer for each example. Work quickly but try not to make errors.

$\begin{array}{llll}11 & 11 & 12 & 9+3= \\ -2 & -8 & -4\end{array}$

32

$26+8=$

96

87

$+87$

$-52$

$-54$

\begin{tabular}{rr}
7 & 8 \\
8 & 5 \\
3 & 6 \\
+6 & +5 \\
\hline
\end{tabular}



$87+6=$
$195+7=$

126

$=54$

449

8

$+87$
139

157

$-84$

$\square \div 2 = 4 \square \div 3 = 8 \quad 4 \longdiv { 1 6 8 }$ \begin{tabular}{rr}
584 & $5 \longdiv { 2 0 5 } \quad 6 9 7$ \\
$\times \quad 5 \times 528=$ \\
\hline
\end{tabular}
$168 \div 7=$
$148 \div 4=$ 
$8 \longdiv { 3 4 4 }$

346

12

$\times 7$

$+1$

$5+3=$

11

$+10$ 